\title{
METHODOLOGICAL DESIGN: EFFECTS OF A MORPHOLOGICAL APPROACH FOR DIFFERENT STUDENTS AND PROFESSIONALS
}

\author{
Zeiler, Wim \\ TU Eindhoven
}

\begin{abstract}
In connection with a design research project for professional in the Dutch building industry, an educational project was developed, the multidisciplinary master project Integral Design, to prepare our Master students better for their professional life. The concept of an earlier developed integral design workshop for professionals was implemented within the start-up workshop of our masters' project integral design. The frame work of the approach is described as well as the positive effects on the collaboration between the design team members from different disciplines as result of the morphological approach of the Integral Design method. This method was also applied during workshops in different courses about design methodology As basically the same set-up for the workshop was used this allowed us to compare the results of the different students and analyse them. During the different workshop series the effects on the outcome of the conceptual phase of the design process has been investigated. The results of this analysis are presented in the paper and showed some remarkable similarities as well as some differences among the different student groups.
\end{abstract}

Keywords: Collaborative design, Communication, Design methods

Contact:

Zeiler, Wim

TU Eindhoven

The Netherlands

w.zeiler@bwk.tue.nl

Cite this article: Zeiler, W. (2019) 'Methodological Design: Effects of a Morphological Approach for Different Students and Professionals', in Proceedings of the 22nd International Conference on Engineering Design (ICED19), Delft, The Netherlands, 5-8 August 2019. DOI:10.1017/dsi.2019.21 


\section{INTRODUCTION}

Buildings use nearly $40 \%$ of all our energy and thus are responsible for a major part of the effects of Global warming. As the effect of Climate change become clearer it is necessary to reduce the environmental load due to buildings. Nearly Zero $\mathrm{CO}_{2}$ Emission Buildings (Karlessi et al., 2016) are needed to prevent further damage to the environment (van der Linden et al., 2016). To make this possible a different approach to building design is necessary (Knotten et al., 2015) which due to increased complexity of building design inevitably calls for more design collaboration (Häkkinen et $a l ., 2015)$. The early collaboration of architects and consulting engineers can facilitate creation of new solutions which lay beyond the specific scope of each individual discipline (Kovacic and Fitzmoser 2014). Design teams should no longer work in a conventional manner: an architect leading the process through the step-by-step improvement of existing features or adding new elements to existing features. The traditional role of the architect must be transferred into a more intensive design collaboration with other disciplines already the conceptual design phase. Engineers and builders therefor must collaborate according to the president Jane Duncan of the Royal Institute of British Architects (RIBA) architects (CIBSE 2016). However, the needed collaboration in the early design phase is not easy for the architects as engineers 'speak another language', which are often 'too specialized', and 'not willing to compromise on certain issues' (Kanters et al., 2014). However, arriving at consensus can be challenging for teams (Kovic et al., 2014) and is affected by cognitive diversity (Kiernan et al., 2017). As stated by Kovic et al. (2014), the engineer needs to learn to think "the unthinkable" and to dare to be creative, whereas the architects need to understand the language of construction and optimization retionales. The process requires open-mindedness and readiness to listen and talk on the same eyelevel with each other. There is a clear need for a design support tool to facilitate collaboration between the various design team's members. However, this is difficult to achieve and this is why in 2001 the Dutch professional organizations of architects (BNA) and consulting engineers (NL Ingenieurs) started together the project Integral Design aimed to improve the cooperation especially in the conceptual design phase.

\section{METHODOLOGY}

This led to research with workshops organized with the professional organizations to test a specific design method based on Methodical Design and the extensive use of Morphological Charts and Morphological Overviews (Savanovic 2009, Quanjel 2013). In these workshops the conceptual design phase was seen as a black-box, see Figure 1, and was analysed what took place.

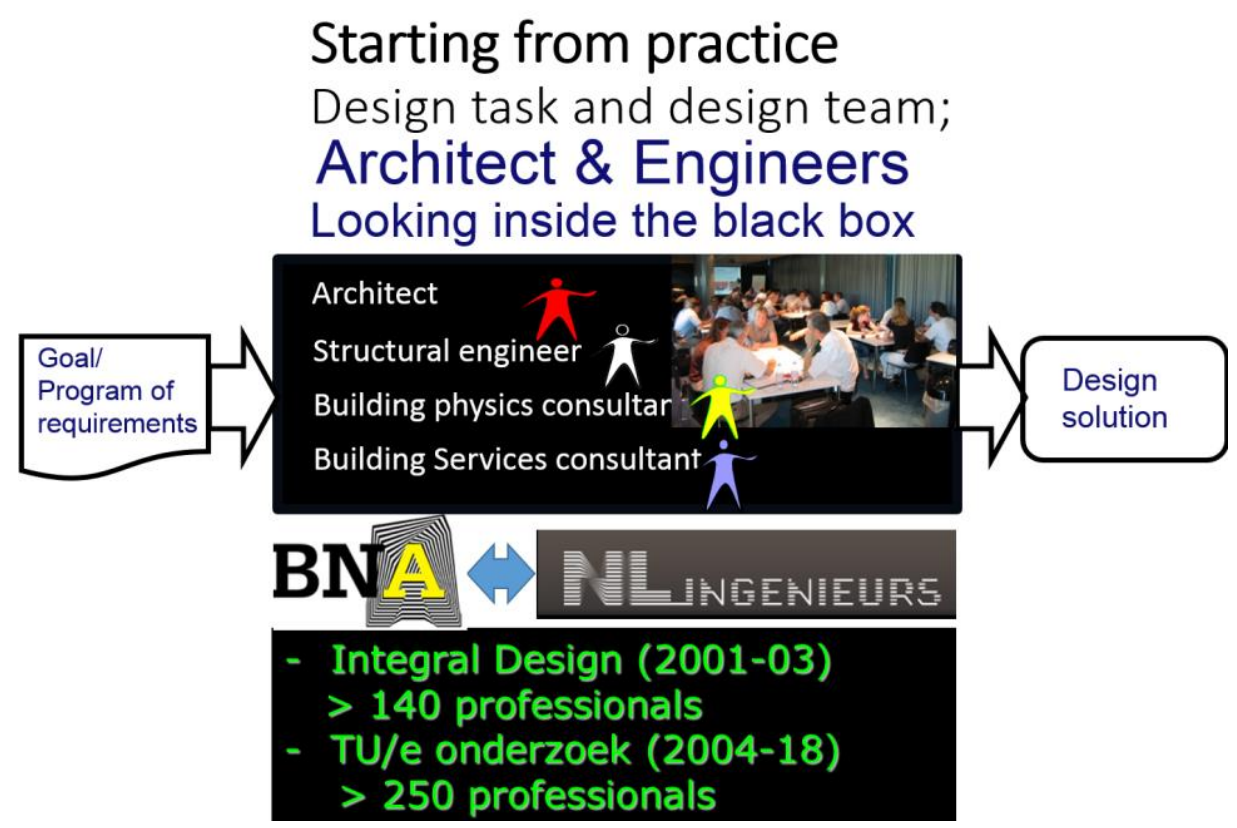

Figure 1. Black-box approach to analyse the conceptual building design phase 
The participants, in total around 390, were all professionals with at least 12 years of experiences and participated in a course as part of their continuous professional education program. This enabled the investigation within a controlled setting as near to professional practice as possible. This research project was continued and implemented in the educational program of the Faculty of the Built Environment of the TU Eindhoven. The design method, with its four major process steps (interpretation, generating, selecting and shaping is completely described in the Handbook design (Zeiler 2017). In step 1, see Figure 2, the different design team member's based on their own individual interpretation of the design brief formulates the most important functions or aspects to be fulfilled in the first column of the morphological charts.
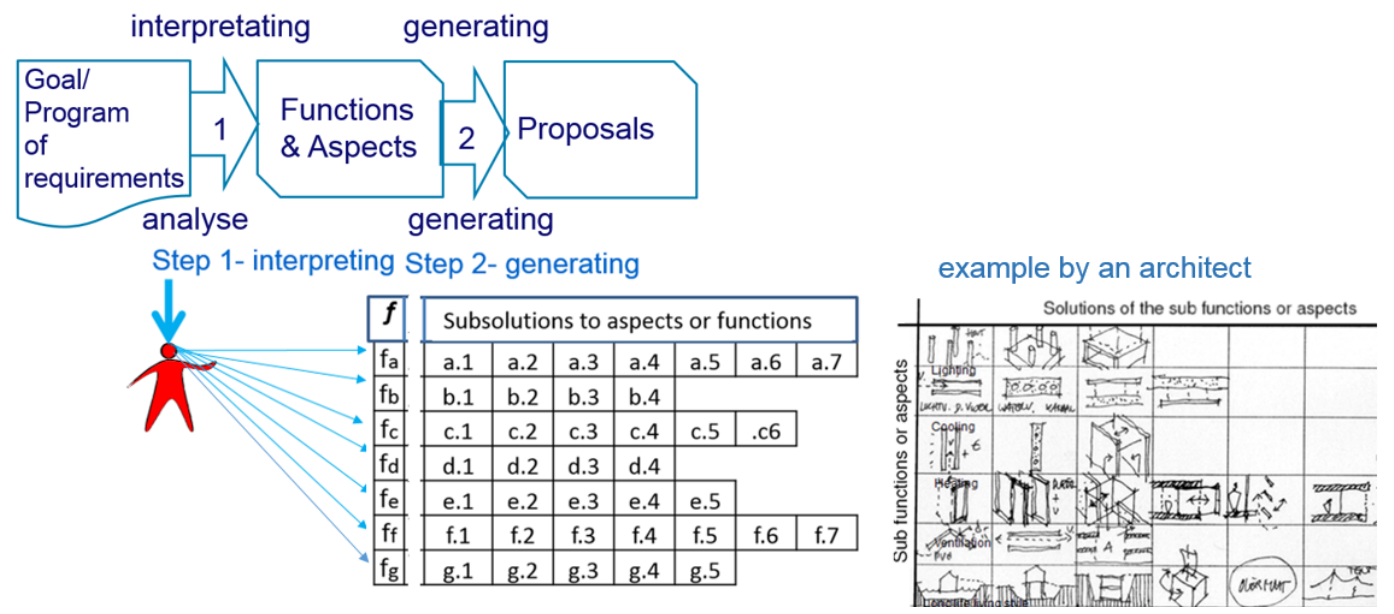

Figure 2. The first two design steps of the design process cycle

Then in the second step the designer fills the rows with the possible sub-solutions connected to listed functions or aspects. So in the first step of the integral design method the individual designer has to make a list of what he thinks, based on his own specialist perspective, are the most important functions or aspects that have to be fulfilled in relation to the design brief. This is then put into the first column of the morphological chart. In the second step of the process, the designers add the possible part solutions to the related rows of the functions/aspects of the first column. Individual morphological charts can be combined by the design team to form one morphological overview, see Figure 3 , step $1^{\mathrm{T}}$ and $2^{\mathrm{T}}$.

Putting the morphological charts together enables 'the individual perspectives from each discipline to be put on the table', which in turn highlights the implications of design choices for each discipline.

The number of functions and sub-solutions mentioned by the designers in their morphological charts and the design team's morphological overview were counted, for an example see Table 1.

Table 1. Number of mentioned functions/aspects as well as sub solutions in the individual morphological charts and the design team's morphological overview

\begin{tabular}{|l|r|r|}
\hline & Number functions/aspects & Number functions/aspects \\
\hline Morphological Chart designer 1 & 11 & 38 \\
\hline Morphological Chart designer 2 & 11 & 25 \\
\hline Morphological Chart designer 3 & 10 & 41 \\
\hline Morphological Chart designer 4 & 10 & 27 \\
\hline Morphological Overview Team & 13 & 54 \\
\hline
\end{tabular}

Unfortunately in the conceptual phase of the design it is rather difficult and labour intensive to accurately evaluate the quality of the mentioned functions/aspects or sub-solutions. Therefor only a quantitative analysis was done by counting the number of mentioned functions/aspects and subsolutions in the individual morphological charts and the team's morphological overview. Due to the fact that only after the discussion within the team functions/aspects and sub solutions were accepted for the morphological overview the overall quality of the functions/aspects and sub solutions is in general on a higher qualitative level. If the mentioned items from the morphological charts are not relevant enough the design team would not include them in the morphological overview. 


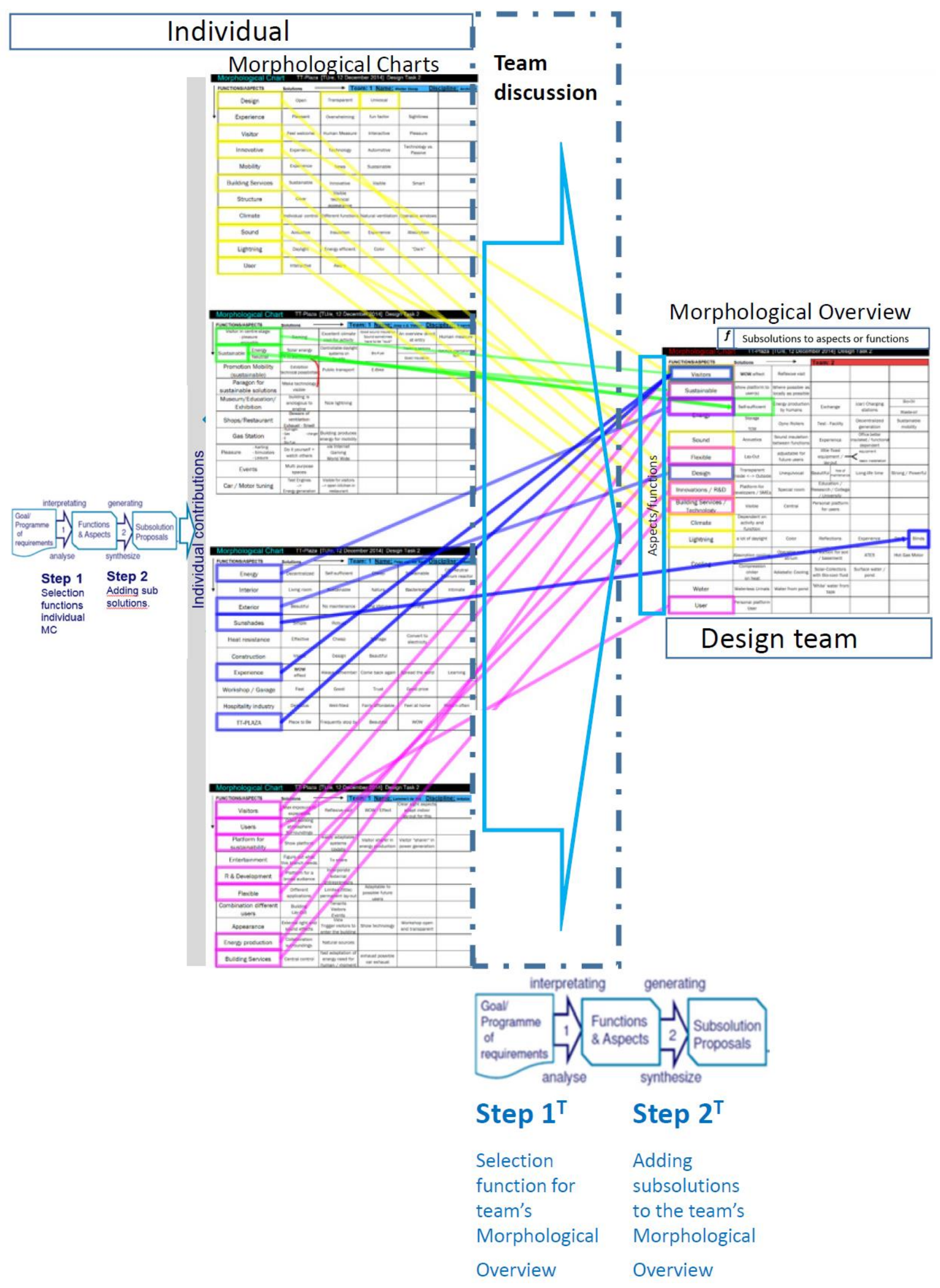

Figure 3. An example of the transformation of the individual morphological charts into a morphological overview, indicated the functions/aspect in the morphological overview and where they came from 


\section{RESEARCH QUESTIONS}

Design education has moved towards a collaborative practice where students work in design teams with other disciplines to solve the design tasks (Kierman et al., 2019). Especially the conceptual design phase is important on the effectiveness of the design process as well as on the final outcome. In this phase major decisions have to be taken based on incomplete information. Therefor it is important to focus on this phase and to study effects of the method to different students groups as we want to prepare our students in the best possible way to generate added value to the current design practice in industry. The literature review (Ho 2001, Ahmed et al., 2003, Goldtschmidt 2013, Björklund 2013, Seidel and Fixson 2013, Kok et al., 2016, Self et al., 2017, Sola et al., 2017, Mosely et al., 2018, Jagtap 2018, Kierman et al., 2019) suggests a significant difference between both student groups, novice and more experienced ones, therefor made it interesting to further research this aspect.

Our main aim is therefor to investigate the effect of the proposed design method to different student groups, especially Bachelor and Master students to see whether the method is more effective for one of the groups. One underlying assumption is that the students need to have some design experience and domain knowledge to really understand the added value of the method, otherwise it could be that without that prior experience students are more open minded to accept the method and thus would have more benefit from it. This study has three hypotheses. They are:

1) Senior Master students will have higher level of creative ability than freshman participants resulting in more generated sub solutions

2) Senior master students will have higher critical thinking abilities than freshman resulting in less mentioned functions

3) In more diverse Bachelor student design teams more different functions are being mentioned leading to in total more sub solutions

\section{EXPERIMENT: START-UP WORKSHOPS DESIGN}

In connection with the Integral design research project for professional in the Dutch building industry, we developed an educational project, the master project Integral Design (Savanovic 2009). The concept of the integral design workshop for professionals was implemented within the start-up workshop of our multidisciplinary masters' project. The different design assignment all were related to the design of zero energy buildings. These complex tasks require early collaboration of all design disciplines involved in the conceptual building design and as such let the students experience the added value of the design method. Master students from the faculty of the built environment, students architecture, building physics, building services, building technology and structural engineering participated in these projects. Besides for the master students also workshops were organized in a course for bachelor students from the faculty of the built environment and the faculty of Business innovation. The basis of the workshop is the Integral design method (Zeiler 2015) with extensive use of morphological charts combined to a morphological overview of the design team. The frame work of the approach is presented in Figure 4.

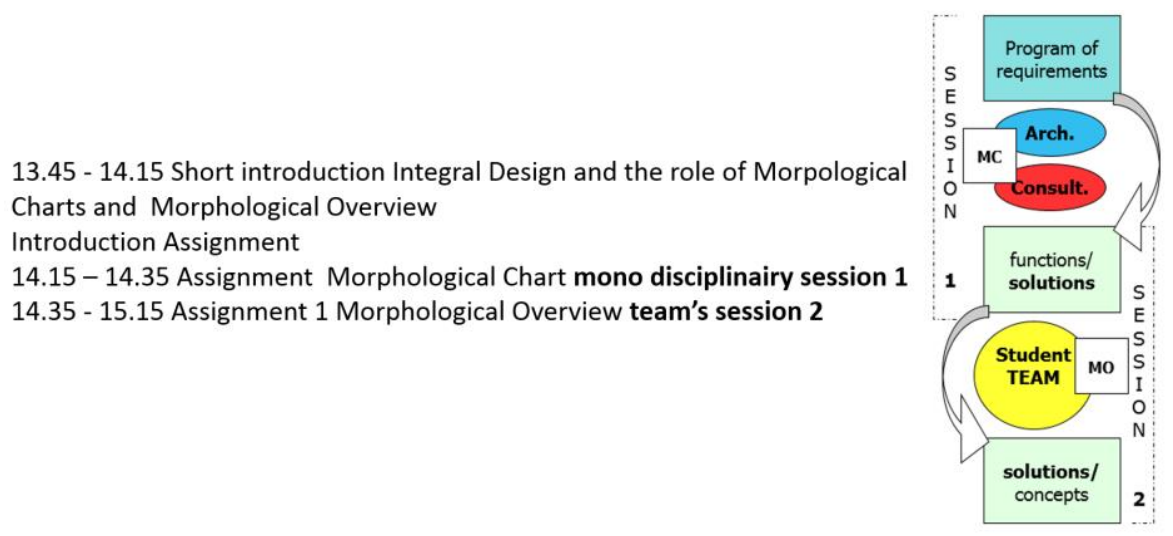

Figure 4. Program and set-up of start-up workshop session 1 and 2

The same assignment was used during all workshops and which was developed within the research of Savanovic (2009). In the first step all participants made in complete silence their individual 
morphological charts, after which in the second step they all brought it to the table to discuss with the other team members to include, see also Fig. $2 \& 3$. To investigate the effect of the morphological tools of the Integral design approach they were used in similar workshops setting for different types of students and professionals;

\section{- Bachelor students}

The students of the course in which the workshop was held were 2nd and 3th year bachelor students, age around 20-22, all Dutch. The students were from the Faculty of the Built Environment and of the Faculty of Psychology and Technology.

- Master students

These were 4th year students (architectural, structural, building physics and building services) all from the Faculty of the Built Environment, age around 22-24.

\section{- Architectural Master students}

One workshop was held for students of architecture all working in a Master thesis project design atelier as part of their MSc graduation project. So they were 5th year students who nearly had finished their studies, age around 23-25. This was the only mono disciplinary group in the comparison.

\section{- PDEng students}

The students from the Post Doctoral Engineering (PDEng) program Smart Energy Buildings and Cities (SEB\&C) were from all different International MSc discipline backgrounds, age 24-26.

\section{- Professionals 2019}

In the research of Savanovic (2009) the concept of working with morphological overviews was tested in different series of workshops for professionals, with at least 12 years of experience.

\section{Professionals 2015}

In 2015, the researchers participated in the start-up of a real professional project for the design of a nearly Zero Energy Building (de Bont et al. 2016). The professionals had around 20 year experience.

\section{RESULTS}

Central element of the Integral Design process is the use of Morphological Charts by individual designers which were combined into one Morphological Overview by the design team. During all experiments the design teams existed of different disciplines. The average numbers of functions and solutions as mentioned by the design teams in their Morphological Charts and Morphological Overview are represented in Fig. 5.

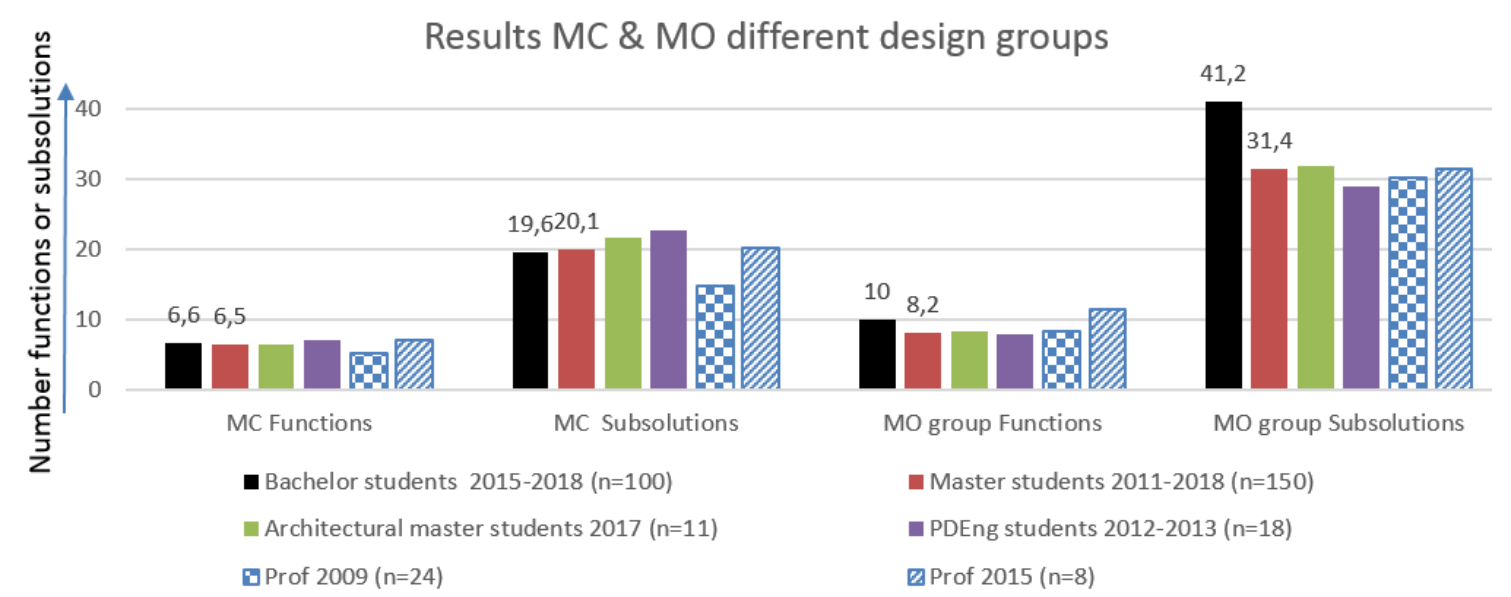

Figure 5. Comparison of the average scores in Morphological Charts \& Morphological Overview by individual students and professionals 
Increase Functions and Subsolutions using MO for different groups

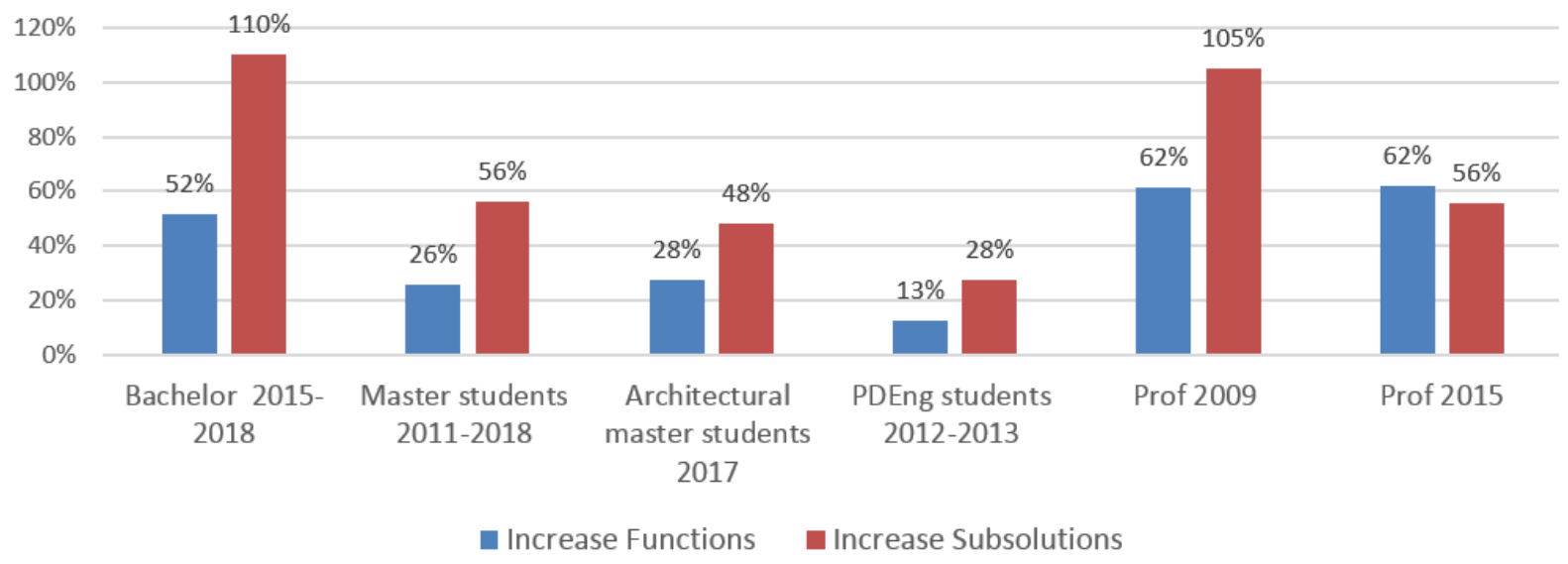

Figure 6. Comparison of the average relative increase in number of functions and sub solutions in their Morphological Overviews compared to the average results from the individual Morphological Charts

Morphological Chart Bachelor students

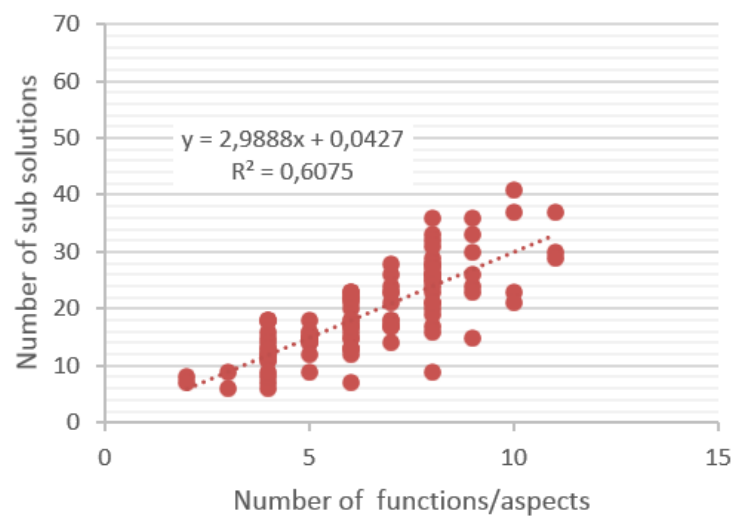

Morphological Overview Bachelor students

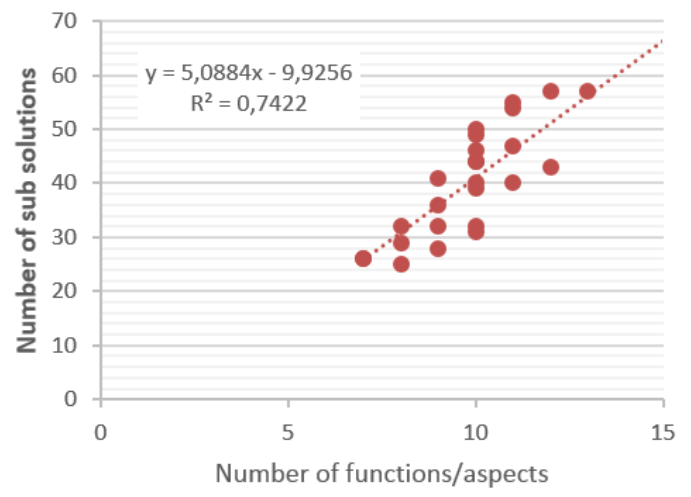

Morphological Chart Master students

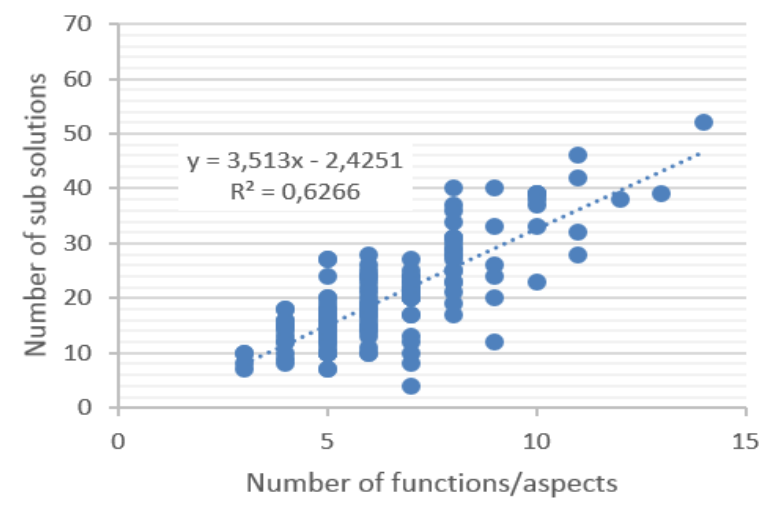

Morphological Overview Master students

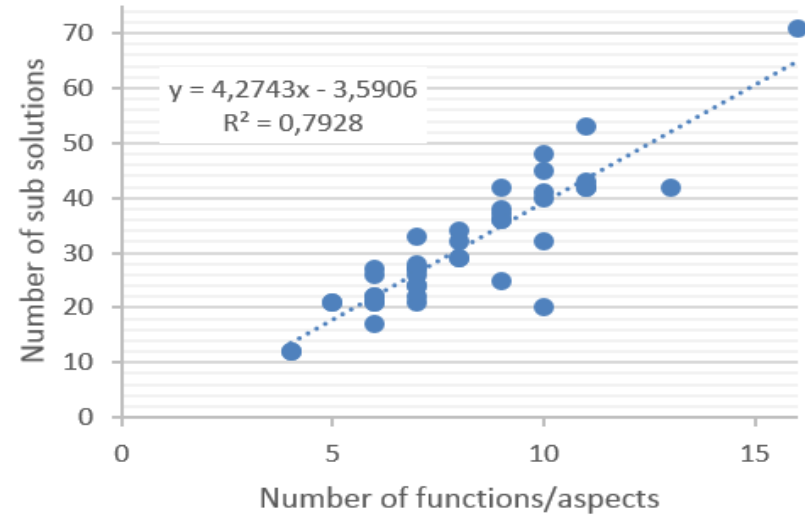

Figure 7. Detailed comparison of the Morphological Charts and Morphological Overviews from Bachelor and Master students

\section{DISCUSSION}

Our research is focused on the conceptual design phase. However, as the sub solutions are put forward in the conceptual design phase, there is no possibility to make a statement about the quality of the mentioned proposals. In this face there is often not enough information, this being gathered during the design process. As the mentioned functions and sub solutions are only accepted after the group's discussion it is assumed that this leads to a higher quality of the included results. The only thing 
further about quality might be that the more functions and aspects are mentioned the broader the analysis of the design brief might be done. Therefor we only performed a quantitative analysis.

The results of individual designers can show large differences, depending on all kinds of aspects relating to personality, social capabilities, attitude etc. of the individuals within the teams. As a result also the outcome of the design teams can show a large variation. In this case we even selected students from our University who all had different educational background and experience, as well as were around the same age.

The Bachelor students mentioned on average 6.6 functions in their Morphological Charts. Remarkable is that these results differ on slightly with those from the Master group, PDEng group and those of the architectual Master group are quite similar: 6.5 - 7.1 - 6.5 functions and $20.1-22.7-21.6$ subsolutions in the morphological chart. The Bachelor students mentioned on average 10 functions in their Morphological Overview. Which remarkably higher than the 8.2 functions of the master students. The most diverse group, that of the Bachelor students had the most benefit of the method: an increase in functions of 52\% compared to $26-28$ - 13\% resp. Master, PDEng, architectural Master student groups and an increase in sub-solutions of $110 \%$ compared to $56-48-28 \%$. From the number of mentioned sub-solutions in the individual morphological charts an increase in the number can be seen the more experience the students get.

The Bachelor students score 19.6 mentioned sub solutions and the Master students score 20.1, so merely $2.5 \%$ higher. The PDEng students scored the highest with 22.7 in their individual Morphological Charts which you of course would expect from their additional educational baggage. However when looking at the effect of the morphological overview the Bachelor students show the highest score of 41.2 sub-solutions as a groups' average, compared to 31.4 for the Master students.

The used morphological overview can be used for further analysis of the conversation and discussion during the transformation of the individual morphological charts into the group's morphological overview, step $1^{\mathrm{T}}$ and step $2^{\mathrm{T}}$ of Fig. 3, through qualitative coding in analogy by the approach applied by Shroyer et al. (2018). In the research by Quanjel (2013) workshop sessions with professionals were analysed in a similar way. However, this approach is enormously time consuming and therefor given the large number of experiments this more in-depth analysis was not applied in this research.

In all situations there was on average a clear positive effect by applying the morphological overview: an increase of number of functions/aspects and sub-solutions mentioned by the team's morphological overview compared to the numbers of the individual morphological charts. However, there were also a very few teams where one of the individual design team members had more functions/aspects mentioned than were taken over in the morphological overview, but these were exceptions.

Especially the design team's discussion while forming the morphological overview will improve their understanding of key issues from each discipline involved in the design process and thus also improve the quality of the mentioned functions and sub-solutions in the morphological overview.

\section{CONCLUSIONS}

A new design approach, Integral Design, was developed to support all the design disciplines involved in the conceptual phase of the building design process by structuring it in steps and applying a morphological approach. The presented intervention to the conceptual phase of the building design process had a positive effect on the number of proposed sub-solutions and also on the amount of functions and aspects considered in this early but crucial important phase of the design process. This indicates that the outcome of the conceptual design phase can largely improve by the added structure to the process.

By applying the morphological charts and morphological overview the conceptual design phase can be analyzed and used to investigate the effects on the design team's process. It enables to reflect on their collaboration process. Integral Design stimulates exchange of ideas and perspectives between designers in the very important early stage of the conceptual design phase. It helps them with their communication and collaboration. In the paper the effect of the method wat tested on different students groups. These results were also compared with results from professionals during workshops as well as from a real project setting in practice.

This study three hypotheses were tested. 
1) Senior Master students will have higher level of creative ability than freshman (Bachelor) participants resulting in more generated sub solutions.

This seemed the case as they mentioned on average $2.5 \%$ more sub solutions in their individual Morphological Charts.

2) Senior master students will have higher critical thinking abilities than freshman (Bachelor) resulting in less mentioned functions.

This is true as the bachelor student included on average 10 functions in their Morphological overview compared to 8.2 for the Master students

3) In more divers Bachelor student design teams more different functions are being mentioned leading to in total more sub solutions.

This also true as the Bachelor students mentioned on average 41.2 sub solutions compared with 31.4 for the master students. Also their relation between mentioned functions and mentioned sub solutions is with 5.089 higher than that of the Master students with only 4.274, see Fig 7. In both cases the $\mathrm{R}^{2}$ values were with respectively 0.74 and 0.79 comparable.

Comparing the professionals with the students, the number of mentioned sub-solutions in the morphological overview did not significantly differ from the outcome of the students, with the exception of the Bachelor students. Clearly this showed that, although they were the least experience participants, their diversity in background and perspective to the design task (more psychological and human oriented, versus more form and technology oriented) compensated more than that. It might be an indication that it would be good to included designers from other than the traditional disciplines would be a good idea to stimulate the generation of sub-solution proposals. Another explanation could be that the younger Bachelor students are less afraid to come up new ideas because they do not know what works.

\section{REFERENCES}

Ahmed, S., Wallace, K.M. and Blessing, L.T.M. (2003), "understand the differences between how novice and experienced designers approach design tasks", Research in Engineering Design, Vol. 14, pp. 1-11.

de Bont, K., Zeiler, W. and van der Velden, J. (2016), "Integral Design method to support nZEB design: a real project experiment," Proceedings Clima 2016, Aalborg, Denmark.

Björklund, T.A. (2013), "initial mental representations of design problems: Differences between experts and novices," Design Studies, Vol. 34, pp. 135-160.

CIBSE (2016), RIBA president wants 'frank debate' on supply chain conflict, CIBSE Journal January 2016.

Goldschmidt, G. (2013), "The design thinking approaches of three different groups of designers based on self reports," Design Studies, Vol. 34, pp. 454-471.

Häkkinen, T., Kuittinen, M., Ruuska, A and Jung, N. (2015), "Reducing embodied carbon during the design process of buildings," Journal of Building Engineering, Vol. 4, pp. 1-13.

Ho, C-H (2001), "Some phenomena of problem decomposition strategy for design thinking: difference between novices and experts," Design Studies, Vol. 22, pp. 27-45.

Jagtap, S. (2018), "Shaping products: Difference between expert and novice industrial designers," Proceedings Design 2018,

Kanters, J., Horvat, M. and Dubois, M. (2014), "Tools and methods used by architects for solar design,” Energy Buildings, Vol. 68 No. part C, pp. 721-731.

Karlessi, T., Kampelis, N., Kolokotsa, D., Santamouris, M., Standardi, L., Isidori, D. and Cristalli, C. (2016), "The concept of smart and nZEB buildings and the integrated design approach, Proceedings International High-Performance Built Environment - A Sustainable Built Environment," Procedia Engineering, Vol. 180, pp. 1316-1325.

Kiernan, L., Ledwith, A. and Lynch, R. (2017), "How design education can support collaboration in teams," Proceedings E\&PDE, Oslo, Norway.

Kiernan, L., Ledwith, A. and Lynch, R. (2019), Comparing the dialogue of experts and novices in interdisciplinary teams to inform design education, international Journal of Technology and Design Education, published online January 23th 2019, https://doi.org/10.1007/s10798-019-089495-8

Kok, B.N.E., Slegers, K. and Vink, P. (2016), "Are seat design processes of students similar to those of professionals?," Work, Vol. 54, pp. 1001-1007.

Kovacic, I. and Filzmoser, M. (2014), Designing and Evaluation Procedures for Interdisciplinary BIM Use - An Explorative Study, Engineering Project Organization Conference Devil's Thumb Ranch, July 29-31, Colorado, US.

Kovacic, I., Filzmoser, M. and Denk, F. (2014), "interdisciplinary Design: Influence of Team Structure on project Success, proceedings $27^{\text {th }}$ IPMA World Conress," Procedia - Social and behavioral Sciences, Vol. 119, pp. 549-556. 
Knotten, V., Svalestuen, F., Hansen, G.K. and Laedre, O. (2015), "Design management in the building process A review of current literature," Proceedings 8th Nordic conference on Construction Economics and Organization, Procedia Economics and Finance, Vol. 21, pp. 120-127.

Linden, V., van der Dong, H. and Heylighen, A. (2016), Capturing architect's designerly ways of knowing about users: Exploring an ethnographic approach, Proceedings DS 2016, Brighton, UK.

Mosely, G., Wright, N. and Wrigley, C. (2018), "Facilitating design thinking: A comparison of design expertise," Thinking Skills and Creativity, Vol. 27, pp. 177-189.

Quanjel, E.M.C.J. (2013), Collaborative Design support, PhD thesis, Technische Universiteit Eindhoven, Netherlands.

Savanović, P. (2009), Integral design method in the context of sustainable building design, PhD thesis, Technische Universiteit Eindhoven, Netherlands.

Seidel, V.P. and Fixson, S.K. (2013), "Adopting Design Thinking in Novice Multidisciplinary Teams: The Application and Limits of Design Methods and Reflexive Practices," Journal of Product Innovation Management, Vol. 30 No. 1, pp. 19-33.

Self, J.A. and Back, J.S. (2017), "Interdisciplinarity in design education: understanding the undergraduate student experience," International Journal Technology Design Education, Vol. 27, pp. 459-480.

Shroyer, K., Lovins, T., Turns, J., Cardella, M.E. and Atman, C.J. (2018), “Timescales and ideaspace: An examination of idea generation in design practice," Design Studies, Vol. 57, pp. 9-36.

Sola, E., Hoekstra, R., Fiore, S. and McCauley, P. (2017), "An investigation of the State of creativity and Critical Thinking in Engineering Undergraduates," Creative Education, Vol. 8, pp. 1495-1522.

Zeiler, W. (2015), "Integral design: the new roles for architect and engineers for developing nearly zero energy buildings," Int. J. Innovation and Sustainable Development, Vol. 9 No. 2, pp. 137-156.

Zeiler, W. (2017), Design Handbook, A methodical framework, Noordhoff Uitgevers, Groningen, Netherlands. 